\title{
Effect of Maltodextrin Concentration on Spray Dried Bitter Gourd Powder
}

\author{
D. Srinivas*, N. Vinoda and L. Edukondalu \\ College of Agricultural Engineering, Bapatla, India \\ *Corresponding author
}

\section{A B S T R A C T}

An experiment was conducted to study the effect of different concentrations of

\section{Keywords}

Bitter gourd powder, Maltodextrin concentrations, Spray drying, Feed flow rate, Storage period

\section{Article Info}

Accepted:

22 April 2018

Available Online:

10 May 2018 maltodextrine on spry drying of bittergourd powder. The results showed that after spray drying, initially the water activity, water absorption index (WAI), and bulk density were decreased with increase in maltodextrin concentration and water soluble index, $\mathrm{pH}$, ascorbic acid, reducing sugars and whiteness index were increased with increase in maltodextrin concentration. During the storage period, the water activity, bulk density and reducing sugars were increased and $\mathrm{pH}$, ascorbic acid and whiteness index were decreased gradually. On $45^{\text {th }}$ day of storage, the water activity was high in sample $T_{9}(0.564)$, the bulk density was high in samples $\mathrm{T}_{1} \mathrm{~T}_{8}$ and $\mathrm{T}_{9}\left(0.57 \mathrm{~g} / \mathrm{cm}^{3}\right)$, the WSI was lower in sample $\mathrm{T}_{9}(15 \%)$, WAI was high in $\mathrm{T}_{7}, \mathrm{~T}_{8}$ and $\mathrm{T}_{9}$, whiteness index was lowest in $\mathrm{T}_{3}$ and $\mathrm{T}_{6}$ samples (2.6 and 2.2, respectively), the ascorbic acid content was more in $\mathrm{T}_{1}, \mathrm{~T}_{2}$ and $\mathrm{T}_{3}$ samples i.e., $37.14 \mathrm{mg} / 100 \mathrm{~g}$ and less in $\mathrm{T}_{4}(31.43 \mathrm{mg} / 100 \mathrm{~g})$ sample and reducing sugars was less in $\mathrm{T}_{3}(15.42 \%)$. Finally it was concluded that at the end of the storage period of 45 days, the quality of product was good at $8 \%$ maltodextrine concentration and $15 \mathrm{ml} / \mathrm{min}$ feed flow rate.

\section{Introduction}

Bitter melon (Momordica charantia L.) is a medicinal fruit often used for the treatment of diabetes, due to its content of saponins, phenolics and flavonoids and its antioxidant capacity. The total area of this crop during 2012-13 was 83 thousand hectares and the production was about 940 thousand metric tonnes (Hand book of horticulture, 2014).

It is very effective in inhibiting the growth of HL60 human leukaemia cells and this effect probably contribute in cancer prevention. Rich in nutrients such as glycosides, niacin, riboflavin, sodium, thiamine, ascorbic acid and iron that can be found in the fruit. Antimicrobial are made from seeds, leaves, fruit and bitter oil melon.

It is one of the strongest hypoglycemic available which helps in regulating blood sugar levels. Indians consume bitter melon juice for treating their gastrointestinal problems like stomachache, hemorrhoids and dermatological problems like skin infections. Bitter melon is a natural blood purifier and helps in getting rid of acne naturally. Bitter melon juice also helps in natural weight loss (Nadine et al., 2005). It is rich in iron, $\beta$ carotene and potassium, Vitamins A, B1, B2, $\mathrm{B} 3$ and $\mathrm{C}$, phosphorous and fiber. 
Bittergourd is a seasonal vegetable and need to preserve them to make them available for consumption in off season by extending the shelf life in fresh form or in the processed form. Generally, preservation of bitter gourd was done by different methods such as steeping preservation, processing of bitter gourd into rings, sun drying and dehydration of bitter gourd, hot air drying of bitter gourd slices, etc. Spray drying is widely used in the industry for conversion of a suspension or solution into a dry powder product.

Spray dryers can dry a product very quickly compared to other methods of drying. Spray drying is a process of suspending sprayed liquid particles and moisture removal by hot air to produce high quality products. The dried product from spray dryers can be in the form of powders, granules or agglomerates depending on the physical and chemical properties of the feed, the dryer design and final powder properties desired (Michael, 1993). The high quality of the spray-dried products is due to the protection of the suspended particles by evaporative cooling during the process. The physicochemical properties of the final product mainly depend on inlet temperature, air flow rate, feed flow rate, atomizer speed, types of carrier agent and their concentration. Hence, the present study was taken up to study the effect of concentrations of maltodextrine on quality and shelf life of bitter gourd powder.

\section{Materials and Methods}

Freshly harvested, healthy and unripe (green color) bitter gourd were procured from local vegetable market, bapatla and used for this study. The fruits were cleaned with water to remove all dirt adhering and the pesticide residues. The selected fruits were cut into small pieces and seeds and pith were removed. The sliced samples were pretreated with salt of $8 \% \mathrm{w} / \mathrm{w}$ for $30 \mathrm{~min}$ for removing bitterness.
After pretreating with salt, the samples were washed with water and subjected to blanching with hot water at $60^{\circ} \mathrm{C}$ for $15 \mathrm{~min}$. Juice was extracted from blanched bittergourd slices using juice extractor and concentrated juice by using rotary vacuum evaporator. The carrier agent maltodextrin of $8,10,12 \% \mathrm{w} / \mathrm{v}$ was added to the concentrated bitter gourd juice to increase concentration and to reduce hygroscopicity of the dried powder. Then the concentrated bitter gourd juice was spray dried by using spray dryer (SMST-15, Kolkata) to obtain bitter gourd powder. The concentrated bitter gourd juice was fed in to the drying chamber with feed flow rates of 15, 20 and 25 $\mathrm{ml} / \mathrm{min}$ and inlet air temperature was maintained at $140{ }^{\circ} \mathrm{C}$. The obtained powder samples were stored in LDPE covers under ambient conditions and the shelf life of powder samples were determined by analyzing quality characteristics for every 15 days interval. The sample were named as $\mathrm{T}_{1}(8$ $\%$ maltodextrine and $15 \mathrm{ml} / \mathrm{min}$ feed flow rate), $\mathrm{T}_{2}(8 \%$ maltodextrine and $20 \mathrm{ml} / \mathrm{min}$ feed flow rate), $\mathrm{T}_{3}(8 \%$ maltodextrine and 25 $\mathrm{ml} / \mathrm{min}$ feed flow rate), $\mathrm{T}_{4} \quad(10 \%$ maltodextrine and $15 \mathrm{ml} / \mathrm{min}$ feed flow rate), $\mathrm{T}_{5}(10 \%$ maltodextrine and $20 \mathrm{ml} / \mathrm{min}$ feed flow rate), $\mathrm{T}_{6}(10 \%$ maltodextrine and 25 $\mathrm{ml} / \mathrm{min}$ feed flow rate), $\mathrm{T}_{7}$ (12\% maltodextrine and $15 \mathrm{ml} / \mathrm{min}$ feed flow rate), $\mathrm{T}_{8}(12 \%$ maltodextrine and $20 \mathrm{ml} / \mathrm{min}$ feed flow rate) and $\mathrm{T}_{9}(12 \%$ maltodextrine and 25 $\mathrm{ml} / \mathrm{min}$ feed flow rate).

\section{Water activity}

The water activity of samples was determined with Hygro Lab C1 bench-top meter.

\section{Bulk density}

The bulk density of bitter gourd powder was determined by taking $2 \mathrm{~g}$ of powder in an empty $10 \mathrm{ml}$ graduated cylinder. The ratio of mass of powder $(\mathrm{g})$ and the volume occupied 
(cm3) in the cylinder gives the bulk density (Goula et al., 2004) of powder. The measurements were done in three replications for each sample and mean values were taken.

$\rho_{b}=\frac{W_{s}}{V_{g}}$

Where,

$$
\begin{aligned}
& \rho_{b}=\text { bulk density, } \mathrm{g} / \mathrm{cm}^{3} \\
& W_{s}=\text { weight of sample, } g \\
& V_{s}=\text { volume of the sample, } \mathrm{cm}^{3}
\end{aligned}
$$

\section{WSI and WAI}

Water solubility index (WSI) was measured according to the method of Ahmed et al., 2010. Half gram of bitter gourd powder and $50 \mathrm{ml}$ water were mixed under agitation using magnetic stirrer (CBM5-1042, Rami instruments Div. Vasai, India) at $700 \mathrm{rpm}$ for $5 \mathrm{~min}$. The dispersion was centrifuged at 3000 rpm for 5 min.

The supernatant was collected in a preweighed Petri dish and the residue was weighed after oven drying overnight at $105^{\circ} \mathrm{C}$. The amount of solids in the dried supernatant as a percent of the total dry solids in the original $0.5 \mathrm{~g}$ sample was used as indicator of WSI and WAI was expressed as ratio of sediment sample to the original sample.

WSI $(\%)=\frac{\text { Dry weight of supernatant }}{\text { Dry weight of sample }} \times 100$

$\mathrm{WAI}=\frac{\text { Sediment sample }}{\text { Dry weight of sample }}$

\section{pH}

$\mathrm{pH}$ of the bitter gourd powder samples was determined using a Digital $\mathrm{pH}$ meter (HI98107, Hanna).

\section{Titrable acidity}

Titrable acidity was determined by titrating bitter gourd powder in water against $0.1 \mathrm{~N}$ sodium hydroxide (Ranganna, 2010). About 5$10 \mathrm{~g}$ of bitter gourd powder sample was taken and added with little amount of water and mixed thoroughly. Now the sample solution was titrated against $0.1 \mathrm{~N} \quad \mathrm{NaOH}$ using phenolphthalein as indicator. Appearance of light pink color denotes the end point. The acidity was calculated by using following equation and expressed in percent.

Titrable acidity $(\%)=\frac{\text { Equivalent weight of acid XNormality of NaOH } \times \text { Titer } \times 100}{\text { Weight of sample } \times 1000}$

\section{Ascorbic acid content}

The ascorbic acid content of the powder was determined using 2, 6- dichloroindophenol indophenols (Ranganna, 2010).

\section{Results and Discussion}

\section{Variation in water activity}

Initially water activity of bittergourd powder samples was less in $\mathrm{T}_{7}(0.311)$ and more water activity was observed in $\mathrm{T}_{3}(0.343)$ sample. The water activity increases with decrease in concentration of maltodextrin due to the addition of maltodextrin could increase the total solid content in the feed and thus reduce the water activity of the product (Quek et al., 2007). But during storage period, the water activity in all samples gradually increased due to absorption of moisture. On $45^{\text {th }}$ day of storage, the water activity was high in sample $\mathrm{T}_{9}$ (0.564). Similarly water activity increased with increase in feed flow rate. Higher flow rates imply shorter contact time between the feed and drying air, making the heat transfer less efficient and thus causing lower water evaporation. Due to this reason the water activity was higher at feed flow rate of 25 $\mathrm{ml} / \mathrm{min}$ in sample $\mathrm{T}_{9}(0.564)$ as compared to feed flow rates 15 and $20 \mathrm{ml} / \mathrm{min}$ (Fig. 1). 


\section{Variation in bulk density}

The variation is in bulk density of different samples as shown in Figure 2. The bulk density decreased when the maltodextrine concentration increased. After spray drying of bittergourd juice, initially the bulk density of bitter gourd powder was observed less in $12 \%$ concentrations as compared with 10 and $8 \%$ maltodextrine concentrations. During the 45 days storage period of bitter gourd powder, the bulk density gradually increased. On 45th day of storage, the bulk density was high in samples $\mathrm{T}_{1} \mathrm{~T}_{8}$ and $\mathrm{T}_{9}\left(0.57 \mathrm{~g} / \mathrm{cm}^{3}\right)$.

\section{Variation in water soluble index}

From the Figure 3, it was observed that after spray drying at an inlet air temperature of $140^{\circ} \mathrm{C}$, initially WSI was more in $\mathrm{T}_{9}(12 \%$ maltodextrine and $25 \mathrm{ml} / \mathrm{min}$ feed flow rate) i.e. $40.8 \%$ and lowest WSI was observed in $\mathrm{T}_{1}$ ( $8 \%$ maltodextrine and $25 \mathrm{ml} / \mathrm{min}$ feed flow rate) i.e. $33.4 \%$. When maltodextrine concentration in bittergourd powder was increased from $8 \%$ to $12 \%$ the water soluble index was increased. It means water soluble index increases with increase in maltodextrine concentration. This is due to higher maltodextrine concentrations led to a decrease in powder moisture content and an increase in powder solubility. On 45th day of storage, the WSI was lower in sample $\mathrm{T}_{9}(15 \%)$. During the storage period, the absorption of moisture powders increased with increase in maltodextrin concentration (Goula and Adamopoulos, 2008). Hence more moisture content was observed in the samples of $12 \%$ maltodextrine compared to $10 \%$ and $8 \%$ maltodextrine.

\section{Variation in water absorption index}

From the Figure 4, initially WAI was less in $\mathrm{T}_{9}, \mathrm{~T}_{8}(1.814 \%)$ and the highest WAI was observed in $\mathrm{T}_{1}(2.464 \%)$. The results showed that, water absorption index decreases with increase in maltodextrine concentration. The carrier agent maltodextrine could form an outer layer of the drops and alter the surface stickiness of particles due to the transformation into a glassy state. The changes in surface stickiness reduce the particleparticle cohesion resulting in less agglomeration, and therefore, lower water holding capacity of the powders. Increased maltodextrine concentration caused a partial reduction in the powder WAI, although it increases powder moisture content. Agglomeration, which usually occurs in powders with higher moisture content, may contribute to their wetting ability because the liquid penetrates into the pores more easily (Buffo et al., 2002). During the storage period of bitter gourd powder, the WAI was increased gradually and this increase was observed more in the samples of higher maltodextrine concentrations i.e., $\mathrm{T}_{7}, \mathrm{~T}_{8}$ and $\mathrm{T}_{9}$.

\section{Variation in whiteness index}

The whiteness index of powder was lowest in $\mathrm{T}_{3}$ (6.8) and highest in $\mathrm{T}_{6}$ (10.1) sample as shown in Figure 5. If the white index of the sample is more, the chlorophyll content will be less in the bittergourd powders. The whiteness index was observed highest in 12\% maltodextrine concentration. The whiteness index was increased with increase in maltodextrine concentration and inlet air temperature.

During the storage period, the whiteness index was decreased and it was lowest in $\mathrm{T}_{3}$ and $\mathrm{T}_{6}$ samples (2.6 and 2.2, respectively) as compared to other samples and more chlorophyll content was observed in $\mathrm{T}_{4}$ and $\mathrm{T}_{7}$ samples (4.4). As the storage period increased, the whiteness index of powder decreased due to absorption of moisture content thus causing non-enzymatic browning resulting in color change. 
Fig.1 Variation in water activity of spray dried powder during storage

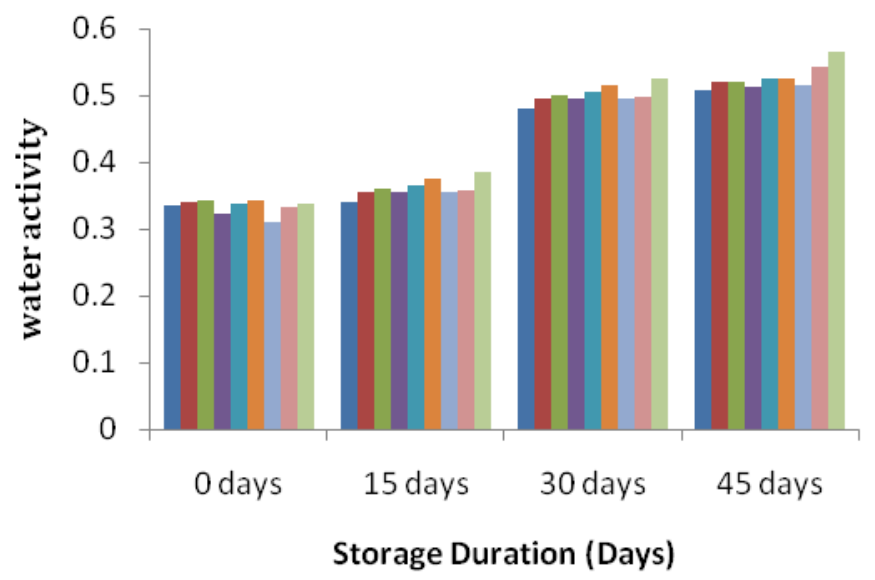

— $8 \%, 15 \mathrm{ml} / \mathrm{min}$

- $8 \%, 20 \mathrm{ml} / \mathrm{min}$

- $8 \%, 25 \mathrm{ml} / \mathrm{min}$

— $10 \%, 15 \mathrm{ml} / \mathrm{min}$

- $10 \%, 20 \mathrm{ml} / \mathrm{min}$

-10\%, $25 \mathrm{ml} / \mathrm{min}$

- $12 \%, 15 \mathrm{ml} / \mathrm{min}$

$12 \%, 20 \mathrm{ml} / \mathrm{min}$

$12 \%, 25 \mathrm{ml} / \mathrm{min}$

Storage Duration (Days)

Fig.2 Variation in bulk density of spray dried powder during storage

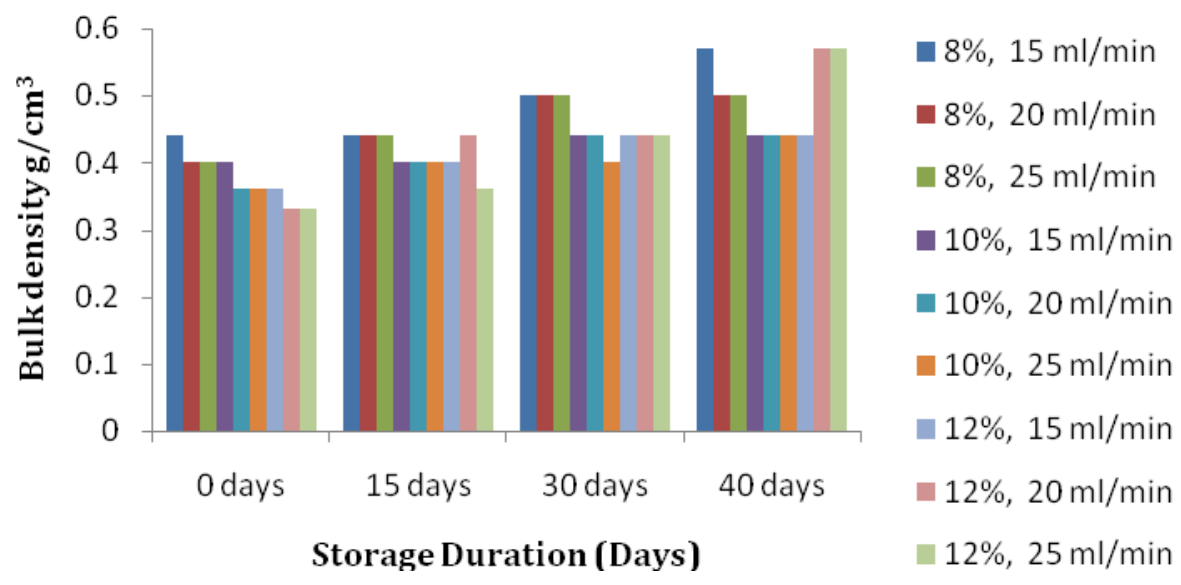

Fig.3 Variation in water soluble index of spray dried powder during storage

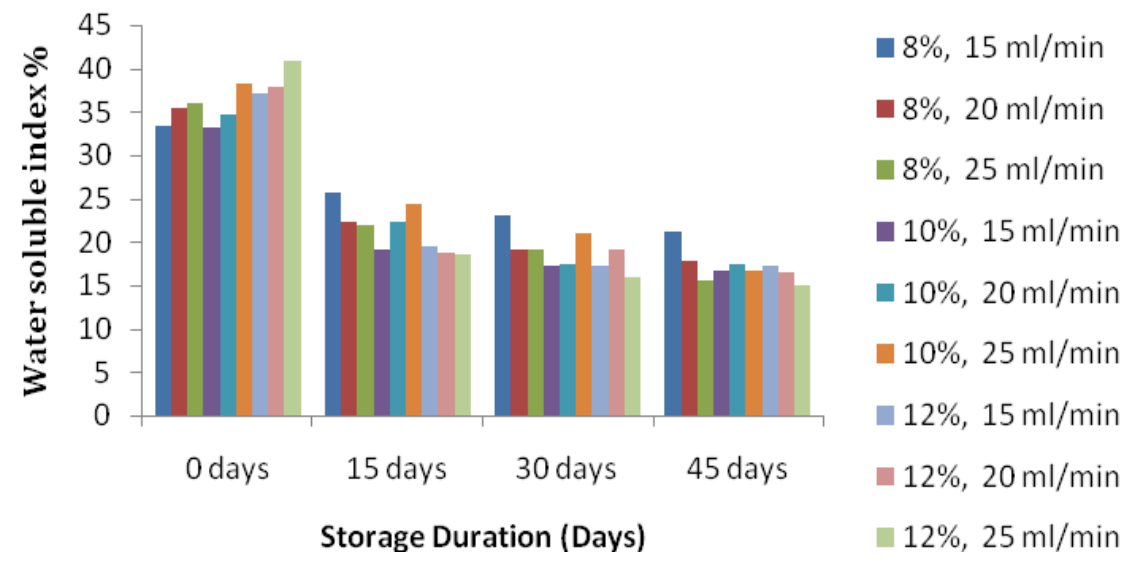


Fig.4 Variation in water absorption index of spray dried powder during storage

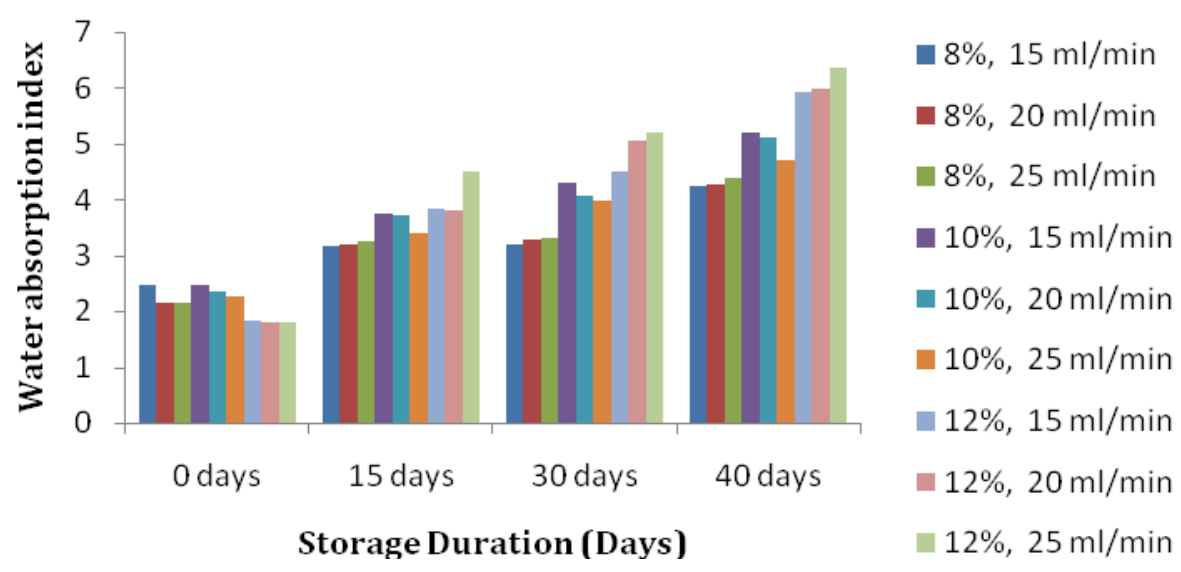

Fig.5 Variation in whiteness index of spray dried powder during storage

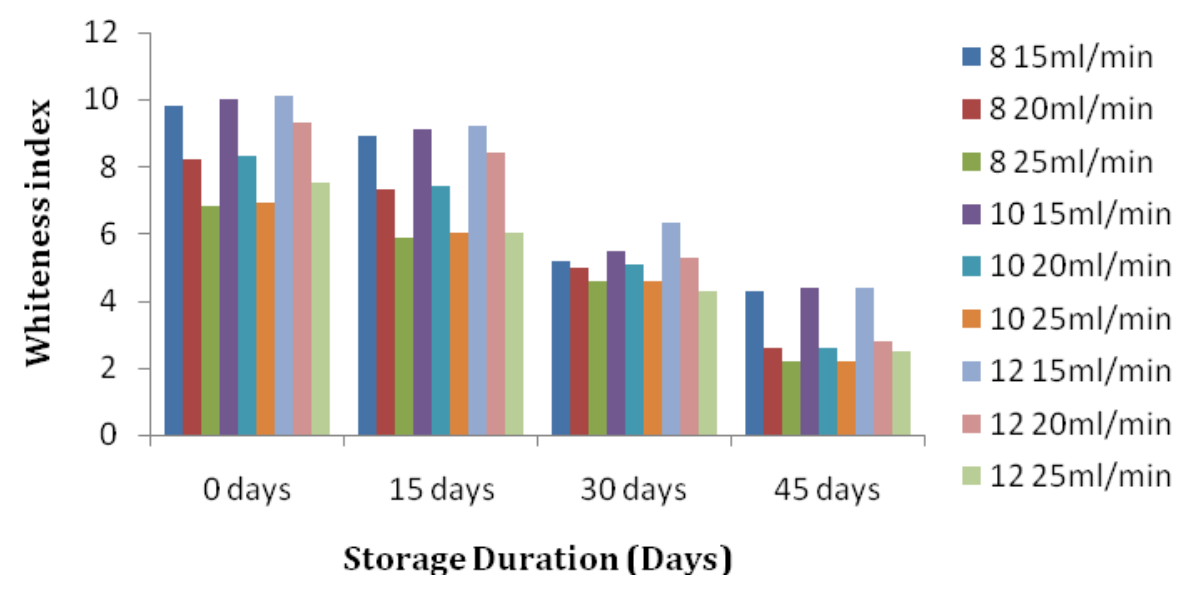

Fig.6 Variation in $\mathrm{pH}$ of spray dried powder during storage

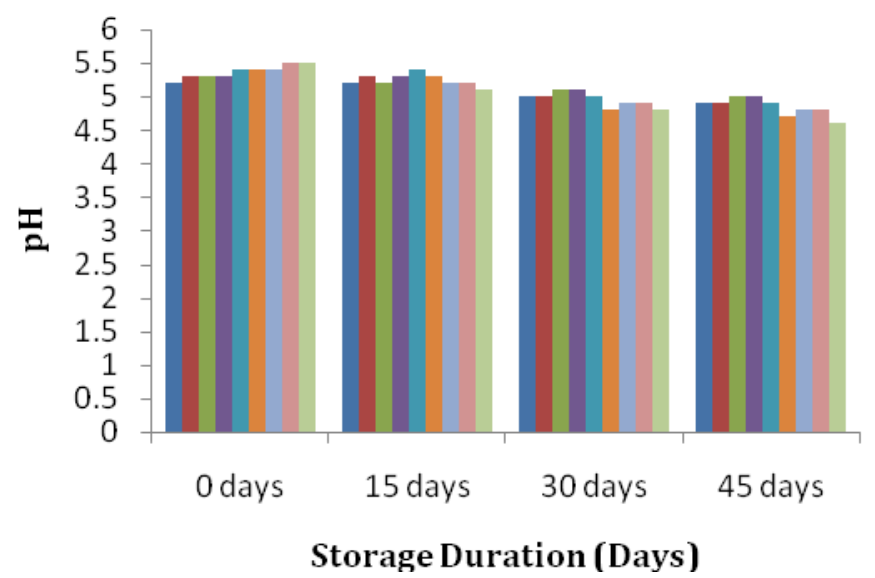
$8 \%, 15 \mathrm{ml} / \mathrm{min}$
— $8 \%, 20 \mathrm{ml} / \mathrm{min}$
- $8 \%, 25 \mathrm{ml} / \mathrm{min}$
- $10 \%, 15 \mathrm{ml} / \mathrm{min}$
- $10 \%, 20 \mathrm{ml} / \mathrm{min}$
$10 \%, 25 \mathrm{ml} / \mathrm{min}$
$12 \%, 15 \mathrm{ml} / \mathrm{min}$
- $12 \%, 20 \mathrm{ml} / \mathrm{min}$
$12 \%, 25 \mathrm{ml} / \mathrm{min}$ 
Fig.7 Variation in ascorbic acid of spray dried powder during storage

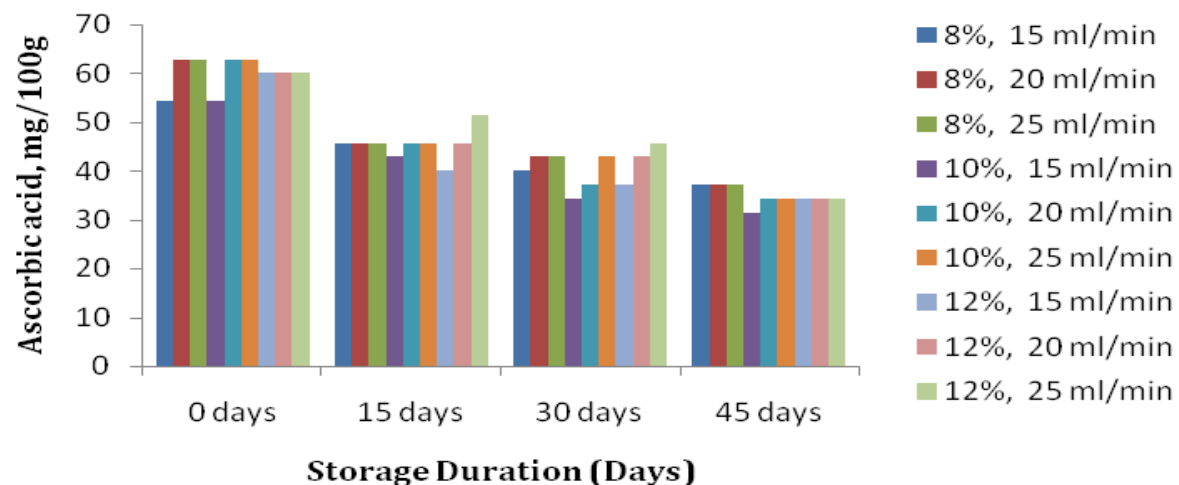

Fig.8 Variation in reducing sugars of spray dried powder during storage

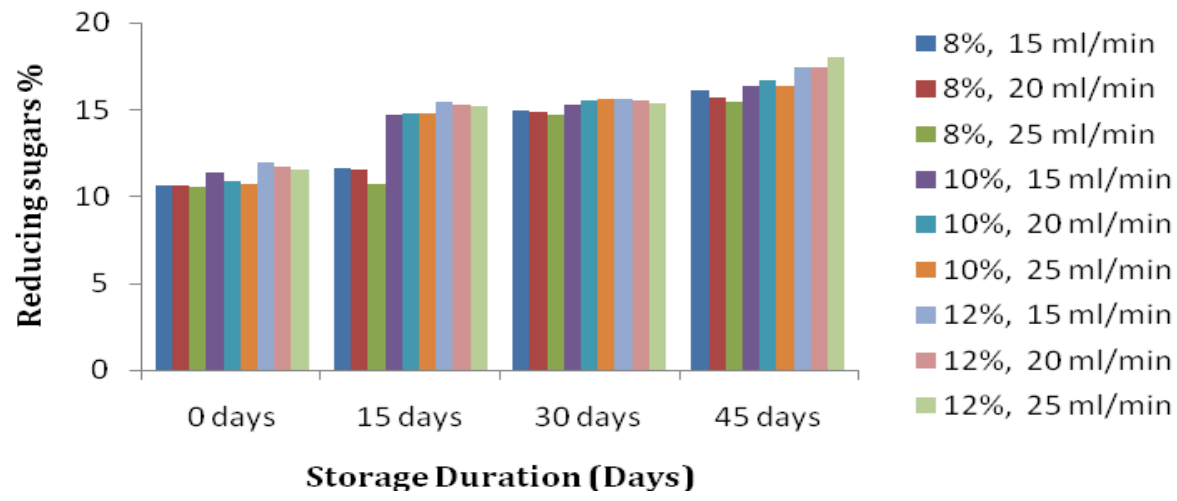

\section{Variation in $\mathbf{p H}$}

The $\mathrm{pH}$ of spray dried bitter gourd powders was almost same in all treatments. The $\mathrm{pH}$ was observed slightly less in $10 \%$ maltodextrin concentrations and increased with increase in maltodextrin concentration (Fig. 6).

The $\mathrm{pH}$ values obtained ranged from 5.2 to 5.5 at an inlet air temperature $140^{\circ} \mathrm{C}$. During storage, the $\mathrm{pH}$ decreased due to the production of acetic acid and lactic acid. At $45^{\text {th }}$ day of storage, the $\mathrm{pH}$ of powder decreased from 5.5 to 4.6 in $\mathrm{T}_{9}$ sample.

\section{Variation in ascorbic acid}

The ascorbic acid content of bitter gourd powder was highest for $\mathrm{T}_{2}, \mathrm{~T}_{3}, \mathrm{~T}_{5}$ and $\mathrm{T}_{6}(62.86$ $\mathrm{mg} / 100 \mathrm{~g}$ sample) and was lowest for $\mathrm{T}_{1}$ sample $(54.29 \mathrm{mg} / 100 \mathrm{~g})$ as shown in Figure 7.

On 45th day of storage period, the ascorbic acid content was more in $\mathrm{T}_{1}, \mathrm{~T}_{2}$ and $\mathrm{T}_{3}$ samples i.e., $37.14 \mathrm{mg} / 100 \mathrm{~g}$ and less in $\mathrm{T}_{4}(31.43 \mathrm{mg} / 100 \mathrm{~g})$ sample.

This decrease might be due to the factors such as storage temperature, oxidative enzymes, processing techniques, metal contamination and the presence of atmospheric oxygen in the head space.

\section{Variation in reducing sugars}

The reducing sugars of bitter gourd powder was observed more in $\mathrm{T}_{7}(11.95 \%)$ sample) and less in $\mathrm{T}_{3}(10.53 \%)$ sample as shown in Figure 8. 
The increase in concentration of maltodextrin in samples would result in increase in reducing sugars. At $8 \%$ maltodextrin concentration the reducing sugars was less compared to 10 and $12 \%$ maltodextrin concentrations. During the storage period of bitter gourd powder, the reducing sugars increased gradually. On 45th day of storage period, the increase in reducing sugars was less in $\mathrm{T}_{3}(15.42 \%)$.

The results showed that after spray drying, initially the water activity, water absorption index (WAI), and bulk density were decreased with increasing maltodextrin concentration and water soluble index, $\mathrm{pH}$, ascorbic acid, reducing sugars and whiteness index were increased with increasing maltodextrin concentration. During the storage period, the water activity, bulk density and reducing sugars were increased and $\mathrm{pH}$, ascorbic acid and whiteness index was decreased gradually. On $45^{\text {th }}$ day of storage, the water activity was high in sample $\mathrm{T}_{9}(0.564)$, the bulk density was high in samples $\mathrm{T}_{1} \mathrm{~T}_{8}$ and $\mathrm{T}_{9}$ $\left(0.57 \mathrm{~g} / \mathrm{cm}^{3}\right)$, the WSI was lower in sample $T_{9}$ (15\%), WAI was high in $\mathrm{T}_{7}, \mathrm{~T}_{8}$ and $\mathrm{T}_{9}$, whiteness index was lowest in $\mathrm{T}_{3}$ and $\mathrm{T}_{6}$ samples (2.6 and 2.2 , respectively), the ascorbic acid content was more in $\mathrm{T}_{1}, \mathrm{~T}_{2}$ and $\mathrm{T}_{3}$ samples i.e., 37.14 $\mathrm{mg} / 100 \mathrm{~g}$ and less in $\mathrm{T}_{4}(31.43 \mathrm{mg} / 100 \mathrm{~g})$ sample and reducing sugars was less in $\mathrm{T}_{3}$ $(15.42 \%)$. Finally it was concluded that at the end of the storage period of 45 days, the quality of product was good at $8 \%$ maltodextrine concentration and $15 \mathrm{ml} / \mathrm{min}$ feed flow rate.

\section{References}

Ahmed, M., Akter, M.S. and Eun, J.B. 2010. Peeling, drying temperatures, and sulphite treatment affect physicochemical properties and nutritional quality of sweet potato flour. Food Chemistry. 121-128.

Buffo, R.A., Probst, K., Zehentbauer, G., Luo, Z. and Reineccius, G.A. 2002. Effects of agglomeration on the properties of spraydried encapsulated flavors. Flavour and Fragrance Journal. 17: 292-299

Goula, A.M. and Adamopoulos, K.G. 2004. Influence of spray drying conditions on residue accumulation Simulation using CFD. Drying Technology. 22(5): 11071128

Goula, A.M. and Adamopoulos, K.G. 2008. Effect of maltodextrin addition during spray drying of tomato pulp in dehumidified air: ii. Powder properties. Drying Technology. 26(6): 726-737.

Hand Book on Horticulture Statistics. 2014. Government of India, Ministry of Agriculture. Department of Agriculture and Cooperation. New Delhi. http://agricoop.nic.in/imagedefault/whats new/handbook2014.pdf

Michael, J.K. 1993. Spray drying and spray congealing of pharmaceuticals. Encyclopedia of Pharmaceutical Technology. 14: 207-221.

Nadine, B., Messanvi, G., Akpagana, K., Hudson, J., Komlan, S., Kossi, K. and Arnason, J. 2005. Ethnomedicinal uses of Momordica charantia (Cucurbitaceae) in Togo and relation to its phytochemistry and biological activity. Journal of Ethnopharmacology. 96(1-2): 49-55.

Quek, Y.S., Chok, N.K. and Swedlund, P. 2007. The physiochemical properties of spray dried watermelon powder. Chemical Engineering and Processing. 46: 386392.

Ranganna, S. 2010. Proximate constituents (chapter 1), Vitamins (chapter 5). In: Handbook of Analysis and Quality Control for Fruit and Vegetable Products. McGraw Hill Education Private Limited, pp: 9-16, 105-106.

\section{How to cite this article:}

Srinivas, D., N. Vinoda and Edukondalu, L. 2018. Effect of Maltodextrin Concentration on Spray Dried Bitter Gourd Powder. Int.J.Curr.Microbiol.App.Sci. 7(05): 3147-3154.

doi: https://doi.org/10.20546/ijcmas.2018.705.368 